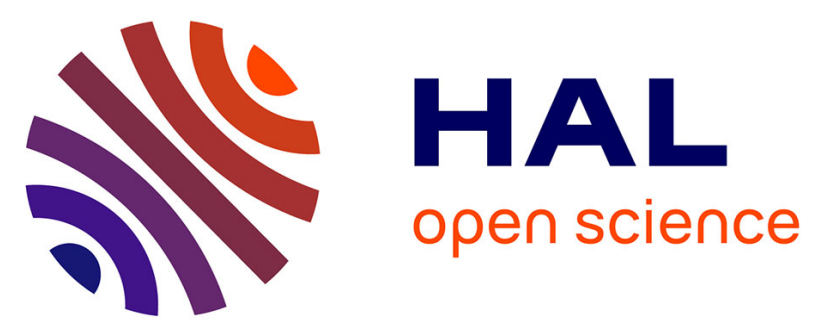

\title{
Dynamic magnetic scalar hysteresis lump model, based on Jiles-Atherton quasi-static hysteresis model extended with dynamic fractional derivatives
}

B. Zhang, B. Gupta, Benjamin Ducharne, G. Sebald, T. Uchimoto

\section{- To cite this version:}

B. Zhang, B. Gupta, Benjamin Ducharne, G. Sebald, T. Uchimoto. Dynamic magnetic scalar hysteresis lump model, based on Jiles-Atherton quasi-static hysteresis model extended with dynamic fractional derivatives. INTERMAG 2018, Apr 2018, Singapore, Singapore. hal-01856306

\section{HAL Id: hal-01856306 https://hal.science/hal-01856306}

Submitted on 10 Aug 2018

HAL is a multi-disciplinary open access archive for the deposit and dissemination of scientific research documents, whether they are published or not. The documents may come from teaching and research institutions in France or abroad, or from public or private research centers.
L'archive ouverte pluridisciplinaire HAL, est destinée au dépôt et à la diffusion de documents scientifiques de niveau recherche, publiés ou non, émanant des établissements d'enseignement et de recherche français ou étrangers, des laboratoires publics ou privés. 


\title{
Dynamic magnetic scalar hysteresis lump model, based on Jiles-Atherton quasi- static hysteresis model extended with dynamic fractional derivatives
}

\section{INTERMAG 2018 - GT 05 - 27/04/2018 - Hysteresis Modelling I}

\author{
B. Zhang ${ }^{1}$, B. Gupta ${ }^{2}$, B. Ducharne ${ }^{2}$, G. Sebald ${ }^{3}$, T. Uchimoto ${ }^{4}$
}

${ }^{1}$ Shandong University, CHINA

${ }^{2}$ Laboratoire de Génie Electrique et Ferroélectricité - INSA de Lyon

Bât. Gustave FERRIE, 8 rue de la physique, 69621 Villeurbanne cedex, France

${ }^{3}$ ELyTMaX, Tohoku University, JAPAN

${ }^{4}$ ELyTMaX, Tohoku University, JAPAN

Corresponding author: Ducharne B.

Benjamin.ducharne@insa-lyon.fr

Tél: +33 (0)4 $72438833 \quad$ Fax: +33 (0)4 72438874

\section{ABSTRACT}

Accurate and simple magnetic material law is necessary to correctly model the complete electromagnetic systems. In this article, a new formulation based on the scalar quasi-static hysteresis Jiles-Atherton model extended to dynamic behavior using fractional derivative dynamic contribution is proposed. The fractional contribution is solved using convolution which highly reduces the numerical issues. The order of the fractional derivation provides a new degree of freedom and allows to obtain correct simulation results on a very large frequency bandwidth. By using such a formulation, highly space and time consuming space discretization techniques (finite differences, finite elements) are avoided while keeping the global accurate simulation results.

\section{KEYWORDS}

Hysteresis, ferromagnetic material, Jiles-Atherton model, fractional derivatives. 


\section{MAIN TEXT}

The development of new electromagnetic designs, such as the improvement of already existing ones require precise simulation tools. These numerical tools can also be used for the estimation of ferromagnetic losses. In the micromagnetic non-destructive testing field, they are used for the understanding and the interpretation of non-destructive control techniques such as eddy current testing, magnetic incremental permeability or magnetic Barkhausen noise [1][2]. Previous scientific progress in the electromagnetic simulation domain mainly focuses on coupling space discretization techniques (Finite Elements Method (FEM), Finite Differences Method (FDM)) to accurate scalar or vector, dynamic or static hysteresis material law [3][4]. For this material law, the best results come from the extension of a vector quasi-static hysteresis contribution (Preisach model [5], Jiles-Atherton model [6]) to a dynamic behavior as it is defined by the separation losses in the Bertotti's theory [7]. Unfortunately, the usual simultaneous resolution of space discretization techniques and hysteresis models can only be performed by time and high memory space consuming iterative techniques. One of them is the so-called fixed point scheme. If the non-linearity levels are weak, this technique gives accurate results whereasfor higher levels (strong hysteresis, saturation) numerical errors are always observed. In this article, an original alternative to space discretization techniques is proposed. In this approach, the space discretization is left behind and the focus is on numerically reproducing the time variations of lump quantities (The cross-section average induction field $B$, and the surface tangent field $H$ ). A few months ago, by extending the Preisach model quasistatic contribution to fractional derivation operators, the authors succeeded in obtaining very accurate simulation results on a very large frequency bandwidth [8]. Unfortunately, the issue here, comes from the Preisach model congruent property, i.e. the similarity of the minor cycles obtained for a given $H$ variations at different levels of $B$. This property becomes real inconvenient, when we try to plot the butterfly loop $|\mu|(H)$ required by the magnetic 
incremental permeability technique [9]. Indeed, using Preisach model $|\mu|(H)$ is limited to just one curve and exhibits no hysteresis. To improve this, a switch from Preisach's model to JilesAtherton's model has been finalized. In this article, we explain with details, how we succeed in simulating the butterfly loop and the $B(H)$ curve on a large frequency bandwidth by extending scalar Jiles-Atherton's quasi-static contribution to dynamic behavior thanks to fractional derivation operators. Fractional derivative is introduced in the lumped quasi-static hysteresis model through a dynamic contribution. Eq. 1 . And fig. 1 gives a quick overview of the model equation, $\mathrm{n}$ is the fractional order and $J . A$ the Jiles-Atherton model.

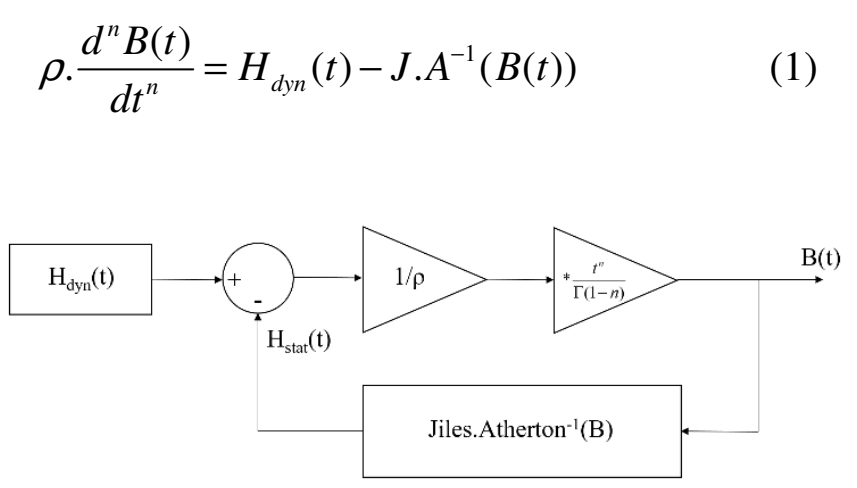

Fig. 1. Block scheme for the Jiles-Atherton extended dynamic model.

Fig. 2 gives a first illustration for the model accuracy by comparing simulation and experimental results for a major hysteresis cycle obtained under dynamic sinus excitation $\mathrm{H}$ $(400 \mathrm{~Hz})$. In the final version of the article, a large number of comparisons simulation/measure will be provided, the good results obtained for the butterfly loop $|\mu|(H)$ will also be illustrated. 


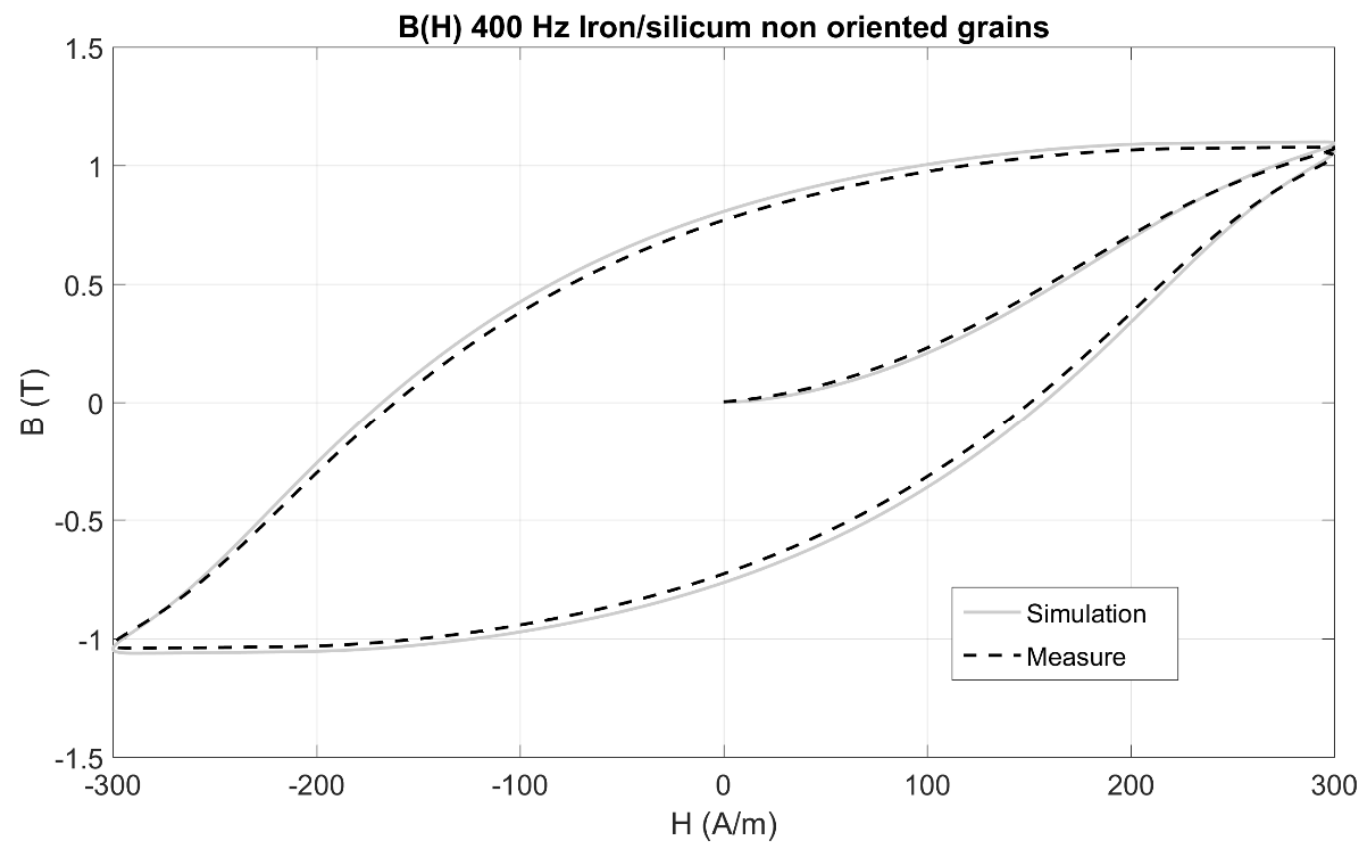

Fig. 2. Comparison of simulation/measurement for Iron/Silicon non-oriented grains under $400 \mathrm{~Hz}$ sinus excitation field $H$.

\section{REFERENCES}

[1] N. Yusa, W. Cheng, T. Uchimoto and K. Miya, "Profile reconstruction of simulated natural cracks from eddy current signals", NDT \& E international, pp. 9-18, 2002.

[2] B. Gupta, B. Ducharne, G. Sebald, T. Uchimoto, A space discretized ferromagnetic model for non-destructive eddy current evaluation, Trans. on mag, 2017.

[3] M. Kuczmann, A. Iványi, "The Finite Element Method in Magnetics”, Budapest, Academic Press, 2008.

[4] M. A. Raulet, B. Ducharne, J.P. Masson, and G. Bayada, "The magnetic field diffusion equation including dynamic hysteresis: a linear formulation of the problem", IEEE Trans. on Mag., vol. 40, n 2, pp. 872 - 875, 2004.

[5] F. Preisach, "Über die magnetische Nachwirkung". Zeitschrift für Physik, 94: 277-302, 1935.

[6] D.C. Jiles, D.L. Atherton, "Theory of ferromagnetic hysteresis". J. App. Pjys. 55, pp. 2115, 1984.

[7] G. Bertotti, "General properties of power losses in soft ferromagnetic materials", IEEE Trans. on Mag.., 24, pp. 621-630, 1988.

[8] B. Zhang, B. Gupta, B. Ducharne, G. Sebald, T. Uchimoto, "Preisach's model extended with Dynamic fractional derivation contribution", IEEE Trans. on Mag, Vol. pp iss. 99, 2017.

[9] A. Yashan, G. Dobmann, "Measurements and semi-analytical modeling of incremental permeability using eddy current coil in the presence of magnetic hysteresis", Electromagnetic Nondestructive Evaluation (VI), F. Kojima et al., IOS Press, 2002. 